\title{
Preparation and Evaluation of Cellulose Acetate Phthalate and Ethyl cellulose based Microcapsules of Diclofenac Sodium using Emulsification and Solvent- Evaporation Method
}

\author{
Md. Mominur Rahman ${ }^{1}$, Md. Saiful Islam², Nahid Sharmin ${ }^{2}$, \\ J akir Ahmed Chowdhury ${ }^{2 *}$ and Reza-ul J alil ${ }^{2}$ \\ ${ }^{1}$ Department of Pharmacy, International Islamic University Chittagong, Chittagong, Bangladesh \\ ${ }^{2}$ Department of Pharmaceutical Technology, Faculty of Pharmacy, University of Dhaka, \\ Dhaka-1000, Bangladesh
}

\begin{abstract}
Diclofenac sodium (DS) microspheres were prepared with two different polymers, ethyl cellulose (EC) and cellulose acetate phthalate (CAP). Emulsification-solvent evaporation method was used to prepare the microspheres. Liquid paraffin containing $1.5 \%(\mathrm{w} / \mathrm{w})$ span 80 was the external phase and acetone-polymer solution was the internal phase. EC and CAP, both as single and as mixture, were used to encapsulate DS. EC microspheres were more spherical in shape and showed more entrapment efficiency than CAP microspheres. The size of the microspheres varied between $560-920 \mu \mathrm{m}$ and as high as $90 \%$ loading efficiency was obtained. In vitro release study was carried out in $0.1 \mathrm{~N}$ hydrochloric acid solution ( $\mathrm{pH}$ 1.2) for first 2 hours followed by in phosphate buffer solution (pH 6.8) for next 4 hours. After first 2 hours of dissolution in $0.1 \mathrm{~N}$ hydrochloric acid, EC microspheres released $24 \%$ of DS whereas CAP microspheres released only $2 \%$ DS. After 4 hours of dissolution in phosphate buffer, $60 \%$ DS was released from EC microspheres and almost all drug was released from CAP microspheres. Combination of EC and CAP showed more sustaining action than the individual polymer in both the dissolution media. DS release from EC microspheres followed Higuchi model whereas CAP microspheres followed first order model.
\end{abstract}

Key word: Diclofenac sodium, microsphere, Ethyl cellulose, Cellulose acetate pthalate

\section{INTRODUCTION}

Diclofenac sodium, a potent non-steroidal antiinflammatory drug with pronounced analgesic properties, is used in the long term treatment of rheumatoid arthritis, osteoarthritis and ankylosing spondylitis. Its biological half-life has been reported as 1-2 hr. ${ }^{1}$ Gastrointestinal side effects such as bleeding, ulceration or perforation of intestinal wall are commonly seen ${ }^{2}$. Due to short biological half life

Correspondence to:

Jakir Ahmed Chowdhury

Tel: +880-2-7219747; Fax: +880-2-8615583

E-mail: jakir@univdhaka.edu

Dhaka Univ. J. Pharm. Sci. 9(1): 39-46, 2010 (June) and associated adverse effects, it is considered as an ideal candidate for controlled drug delivery via sustained release matrix tablets, pellets and sustained release microspheres. ${ }^{3-5}$

Microencapsulation is one process used to control drug release and hence prolong therapeutic activity. ${ }^{6} \quad$ In pharmaceutical sustained release preparations, the uniqueness of microcapsules lies in the wide distribution throughout the gastrointestinal tract. This potentially improves drug absorption and reduces side effects related to localized build-up of irritating drugs against the gastrointestinal mucosa. ${ }^{7}$ 
Many different coating materials and microencapsulation processes can be used. The emulsion solvent evaporation method has been described in the literature, and has been applied to polymers like ethyl cellulose ${ }^{8-9}$ and cellulose acetate phthalate. $^{10-11}$

The purpose of this investigation was to prepare diclofenac sodium microspheres using ethyl cellulose and cellulose acetate phthalate as wall material by emulsion solvent evaporation method; to study the effect of ethyl cellulose and cellulose acetate phthalate on surface property, microsphere size and release profiles of the diclofenac sodium and to fit the data to various postulated drug release models.

\section{MATERIALS AND METHODS}

Materials. The following chemicals were obtained from commercial sources and used as received: Diclofenac sodium (Hugestone Enterprise Co. Ltd, China), Ethyl cellulose (BDH Chemicals, England), Cellulose acetate phthalate (BDH Chemicals, England), Liquid paraffin (Merck, Germany), Acetone (Merck, Germany), Span 80 (BDH Chemicals, England), Hydrochloric acid (Merck, Germany), Petroleum ether of 40:60 grade (Merck, Germany), Tri-sodium phosphate (Merck Limited, Mumbai, India).

Preparation of diclofenac sodium microspheres. Diclofenac sodium microspheres were prepared according to Table 1. $100 \mathrm{gm}$ of liquid paraffin containing $1.5 \mathrm{gm}$ of Span 80 (external phase) was taken in a $250 \mathrm{ml}$ glass beaker. Desired amount of diclofenac sodium was dispersed in the internal phase with stirring at $2000 \mathrm{rpm}$ (Heidolph, 5011, England). The internal phase of polymeric solution (polymer: acetone is 1:5) was then incorporated into the external phase with continuous stirring at $2000 \mathrm{rpm}$. After 2 hours of stirring, hard, spherical microspheres were obtained. Microspheres were then washed three times with petroleum ether (40:60) and vacuum-dried to obtain free flowing microspheres.

Microspheres were also prepared using mixture of EC and CAP as shown in Table 2.
Surface Morphology Study. To observe the surface morphology of the microspheres, a Scanning Electron Microscope (S-3400N, Hitachi, Japan) was used. SEM images at different magnifications were taken for comparative study.

Table 1. Formulation of diclofenac sodium microspheres.

\begin{tabular}{lcccccccc}
\hline Chemicals (gm) & A1 & A2 & A3 & A4 & B1 & B2 & B3 & B4 \\
\hline $\begin{array}{l}\text { Diclofenac sodium } \\
\text { (DS) }\end{array}$ & 2 & 3 & 5 & 8 & 2 & 3 & 5 & 8 \\
$\begin{array}{l}\text { Ethyl cellulose } \\
\text { (EC) }\end{array}$ & 8 & 7 & 5 & 2 & - & - & - & - \\
$\begin{array}{l}\text { Cellulose acetate } \\
\text { phthalate (CAP) }\end{array}$ & - & - & - & - & 8 & 7 & 5 & 2 \\
\hline
\end{tabular}

Table 2. Formulation of DS (5 gm) microspheres using combination of EC and CAP.

\begin{tabular}{lllll}
\hline \multicolumn{2}{l}{ Polymeric Phase } & C1 & C2 & C3 \\
\hline \multirow{2}{*}{5 gm } & EC (\%) & 75 & 50 & 25 \\
& CAP (\%) & 25 & 50 & 75 \\
\hline
\end{tabular}

Particle Size Analysis. Size distribution of the microspheres was analyzed by laser diffraction technique of Mastersizer 2000 (Malvern, UK). Particle size distribution was measured by Dry Dispersion technique. Average particle size was expressed as volume mean diameter (D [4, 3]) and surface weighted mean diameter (D [3,2]) in $\mu \mathrm{m}$.

Quantitative analysis of diclofenac sodium. Aqueous solutions of diclofenac sodium ( 0 to 20 $\mu \mathrm{g} / \mathrm{ml}$ ) in 0.2 molar phosphate buffer ( $\mathrm{pH}$ 6.8) were prepared and the absorbance was measured at $276 \mathrm{~nm}$ by a Shimadzu UV-VIS Spectrophotometer (UV mini-1240, Shimadzu Corp., Kyoto, Japan). A linear line was obtained while absorbance values were plotted against concentrations $\left(\mathrm{R}^{2}>0.996\right)$.

Drug loaded microspheres of each batch were finely powdered in a glass mortar and $10 \mathrm{mg}$ powder was taken in a volumetric flask. A clear solution was made using phosphate buffer after proper sonication (Power Sonic 505, Hwashin Technology co., Seoul, Korea). Then the solution was filtered through 0.45 $\mu \mathrm{m}$ filter and analyzed spectrophotometrically for drug content.

The weight of diclofenac sodium theoretically contained in the microspheres was compared with the weight actually obtained from the drug content 
studies, i.e., the quantity loaded into the microspheres formulated, to get the diclofenac sodium loading efficiency. Following equation was used for the calculation.

Drug-loading efficiency $(\%)=(\mathrm{Cp} / \mathrm{Ct}) \times 100$

where, $\mathrm{Cp}$ and $\mathrm{Ct}$ were the actual and theoretical drug content in diclofenac sodium loaded microspheres, respectively.

In vitro dissolution study. In-vitro dissolution was carried out in a USP XXX apparatus 2 (Paddle Apparatus) in $900 \mathrm{ml}$ of $0.1 \mathrm{~N} \mathrm{HCl}$ solution ( $\mathrm{pH} \mathrm{1.2)}$ for 2 hours followed by in $900 \mathrm{ml}$ of phosphate buffer $\left(\mathrm{pH}\right.$ 6.8) for next 4 hours at $37 \pm 0.5^{\circ} \mathrm{C}$ at a rotational speed of $50 \mathrm{rpm}$. Dissolution Samples were withdrawn at predetermined intervals and were filtered through $0.45 \mu \mathrm{m}$ filters. The drug content was determined in the filtrate either directly or after appropriate dilution with the dissolution media.
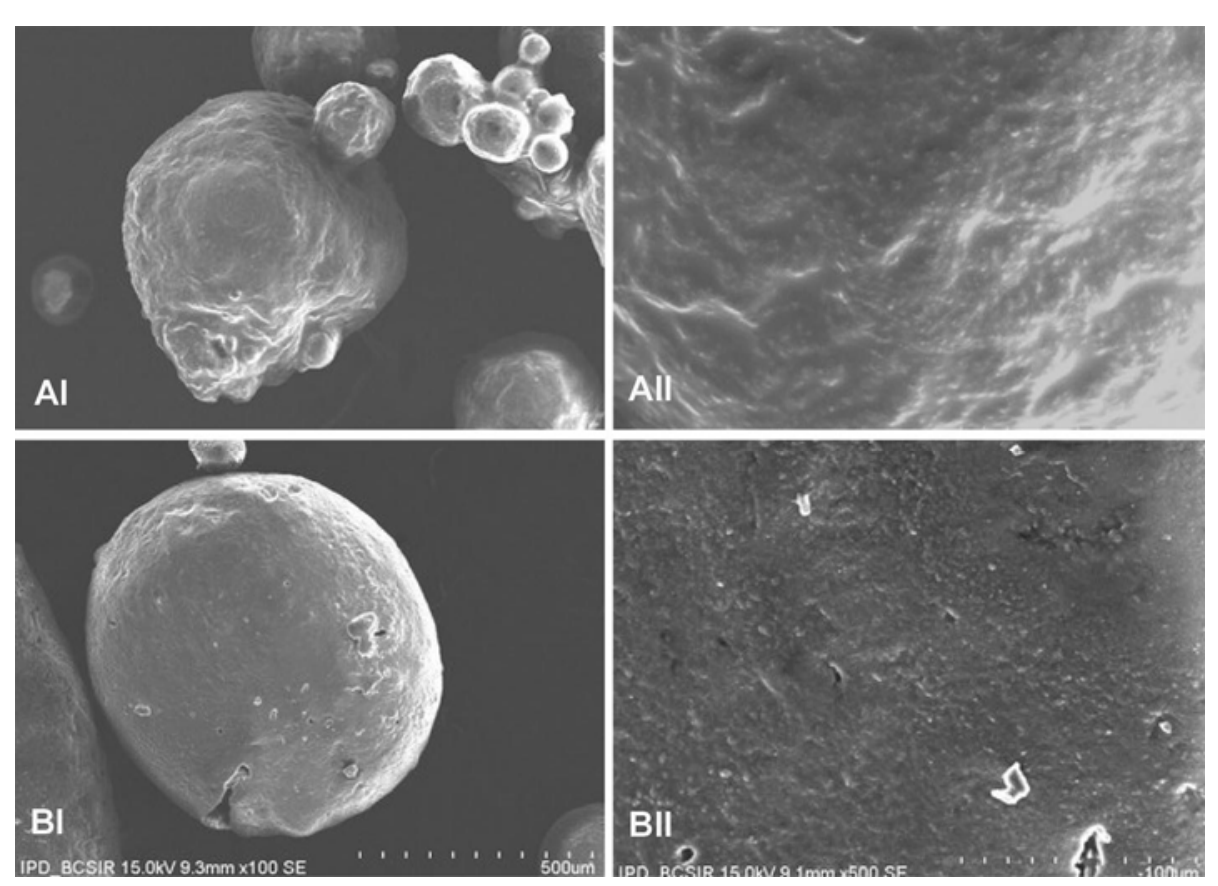

Figure 1. Scanning electron micrograph of diclofenac sodium microspheres prepared with different concentration of EC; $\mathrm{A}=20 \% \mathrm{EC}, \mathrm{B}=80 \% \mathrm{EC}$.

Microsphere surfaces were also significantly changed due to different CAP concentration. In case

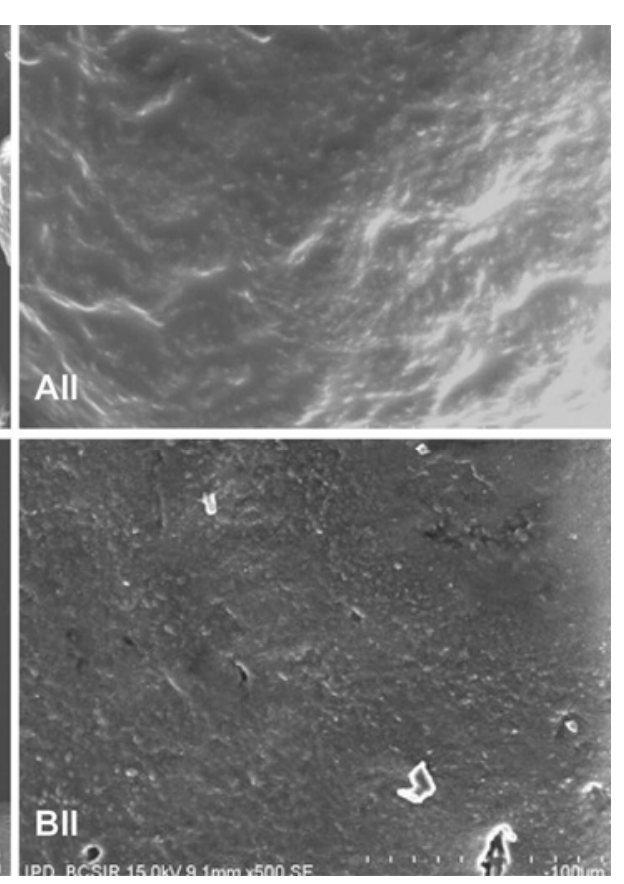

\section{RESULTS AND DISCUSSION}

Diclofenac sodium microspheres were prepared by emulsification and solvent evaporation technique with two different polymeric materials ethyl cellulose (EC) and cellulose acetate phthalate (CAP). Effect of different concentration of $\mathrm{EC}$ and $\mathrm{CAP}$ on the diclofenac sodium microspheres was successfully examined with respect to microcapsule size, surface characteristics, drug loading efficiency, and release kinetics.

Morphology of the microspheres. In Figure 1 and 2, significant differences in the surface characteristics were observed from batch to batch of both types of polymers. While $20 \%$ EC was used, microsphere shape was nearly spherical and surface was rough (Figure 1A). In contrast, while $80 \%$ EC was used, microsphere shape was more spherical and surface appeared more smooth (Figure 1B). This might be due to the less core load in the microspheres of the latter batch. A uniform wall was formed around each microsphere of the latter batch due to high polymeric content also.

of the microspheres comprising 20\% CAP, large holes were seen on the microsphere surface (Figure 
2A). Theoretically, more DS crystals should be present on the microsphere surface as the formulation contained relatively larger amount of the drug. But figuratively, a surface embedded with fewer amounts of DS and containing large holes were seen. This can be substantiated from the previous experiments of the same $\operatorname{drug}^{12}$. Being a water soluble drug, DS remained dissolved in the continuous phase during the gradual progression of the microparticles and fewer amounts of DS was entrapped within the CAP matrix. DS loading efficiency of the formulation was $71.54 \%$ (Table 3, formula B4) and this also indicates the presence of lesser amount of DS in the microsphere matrix. As the CAP concentration was increased to $80 \%$, microsphere surface became smoother and shape became more spherical (Figure 2B).

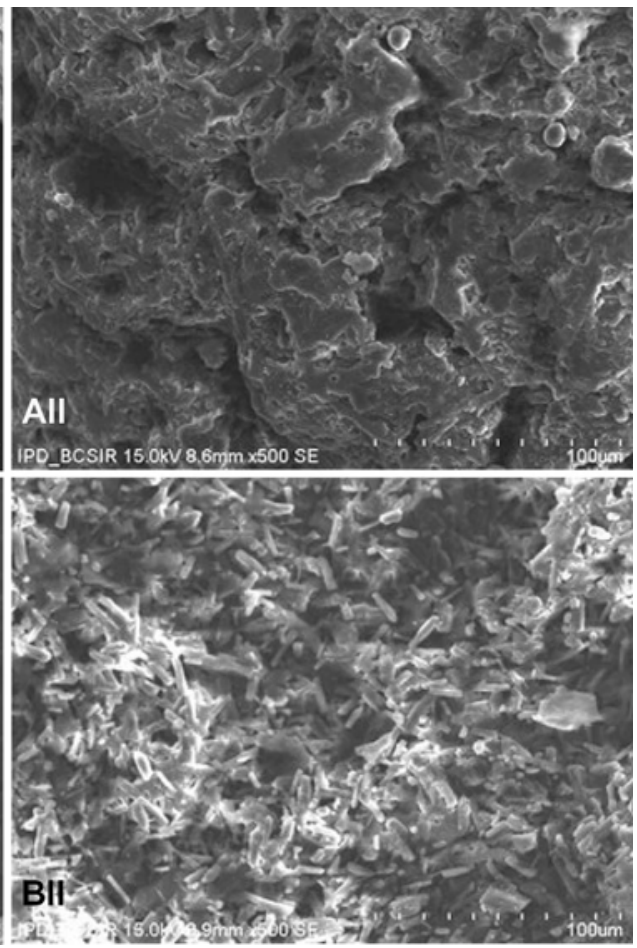

Figure 2. Scanning electron micrograph of diclofenac sodium microspheres prepared with different concentration of CAP; $\mathrm{A}=20 \% \mathrm{CAP}, \mathrm{B}=80 \% \mathrm{CAP}$.

Particle size distribution analysis. Increased amount of polymeric material resulted in increased particle size (see Table 3). Mean particle size was $885.65( \pm 2.54) \mu \mathrm{m}$ for $80 \%$ EC and $523.91( \pm 4.21)$ $\mu \mathrm{m}$ for $20 \%$ EC. Similarly, particle size was 921.34 $( \pm 1.34) \mu \mathrm{m}$ for $80 \% \mathrm{CAP}$ and $563.31( \pm 1.65) \mu \mathrm{m}$ for $20 \%$ CAP. As the polymeric amount was increased, fusion between semi formed microparticles was increased which ultimately produced larger microcapsules ${ }^{13-14}$ (Figure 3). Whereas microspheres, formulated with lesser polymeric materials, were comparatively smaller. Presence of insufficient polymeric material might be attributed to this. Even microspheres formulated with $20 \%$ and $50 \%$ CAP showed a bimodal type of particle size distribution (Figure 3b). As the amount of CAP was comparatively less for these formulations in the medium, semi formed microparticles could not transformed into larger particle by coalescence. And this resulted in the formation of small volume of smaller particles along with the large volume larger particles.

Loading Efficiency. Maximum drug load was $92.65 \%$ for batch A1 (80\% EC) and minimum drug load was $71.52 \%$ for batch B4 (20\% CAP) (Table 3). Higher polymeric content entrapped higher amount of DS. Generally encapsulation efficiency of a drug depends on the solubility of the drug in the organic 
solvent and continuous phase. But, an increase in the concentration of polymer in a fixed volume of organic solvent also results in an increase in encapsulation efficiency ${ }^{15}$. However, encapsulation efficiency of EC was higher than CAP. This might be due to the structural differences of two polymers. Presence of phthalate groups in CAP might impart more lipophilicity to the structure and this made the polymer less favorable for entrapping water soluble DS.
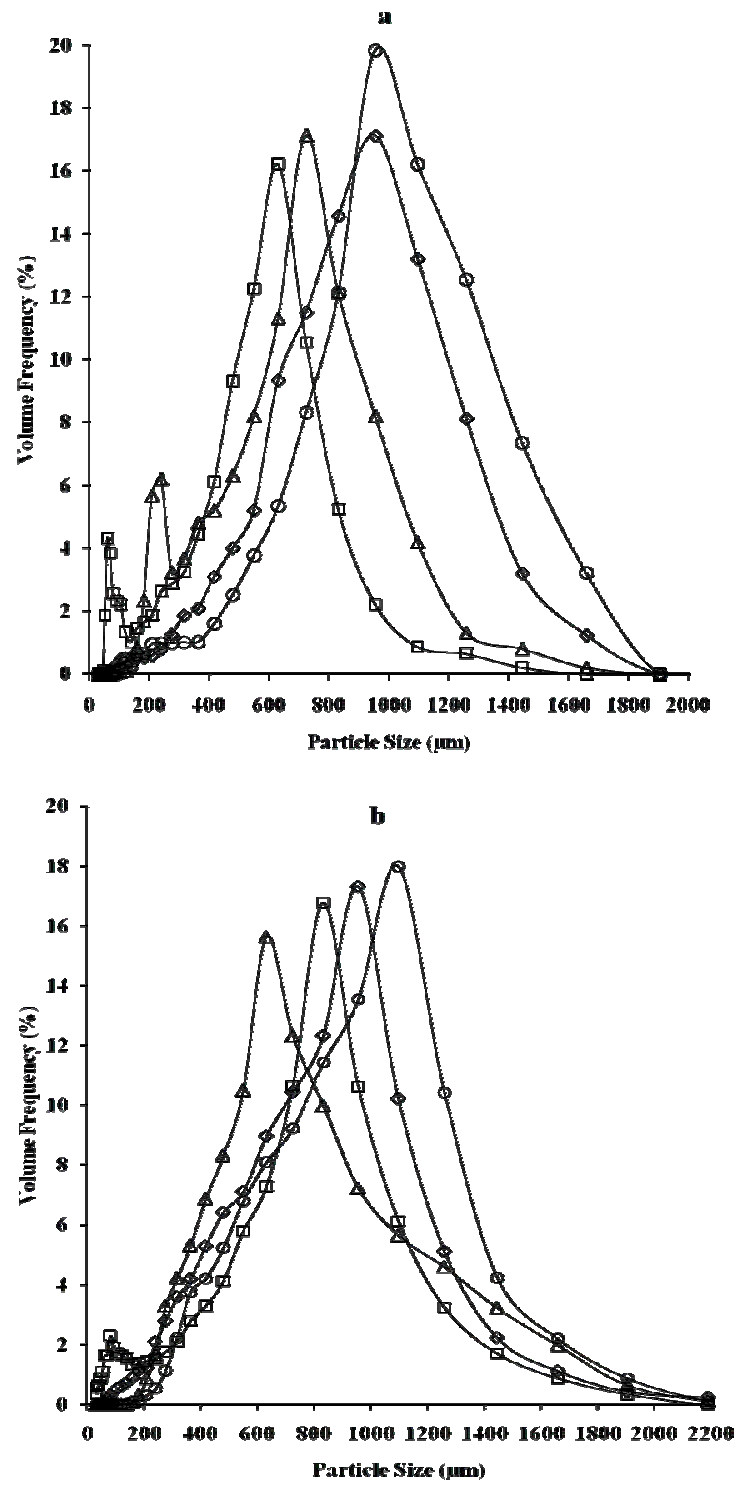

Figure 3. Particle size distribution of diclofenac sodium microspheres prepared with different concentration of EC (a) and CAP (b): $20 \%$ polymer, $\square ; 50 \%$ polymer, $\Delta ; 70 \%$ polymer, $\diamond ; 80 \%$ polymer, $\circ$.
Release Profile. Figure 4 and 5 show the release of diclofenac sodium from the microspheres formulated with EC and CAP respectively. Percent amount of drug release was found to be decreased significantly with increase amount of EC $(p<0.01)$. Though increased amount of CAP reduced DS release in phosphate buffer, less significant effect of CAP on DS release was observed in case of $0.1 \mathrm{~N}$ hydrochloric acid solution $(\mathrm{p}>0.05)$. However, gradual decrease in drug release rate with increased amount of polymer is a very common phenomenon. This can be explained by a decreased amount of drug present close to the surface and also by the fact that the amount of uncoated drug decreases with higher polymer concentration. ${ }^{16-17}$ Lesser amount of CAP was also unable to sustain the DS release even for up to 6 hours. Though batch B1 ( $80 \%$ CAP) and B2 (70\% CAP) released $89.80 \%$ and $99.60 \%$ DS respectively within 6 hours of dissolution, $99.67 \%$ drug was released from batch B3 (50\% CAP) within 5 hours and $99.43 \%$ drug was released from batch B4 (20\% CAP) within 4 hours (Figure 5) of dissolution.

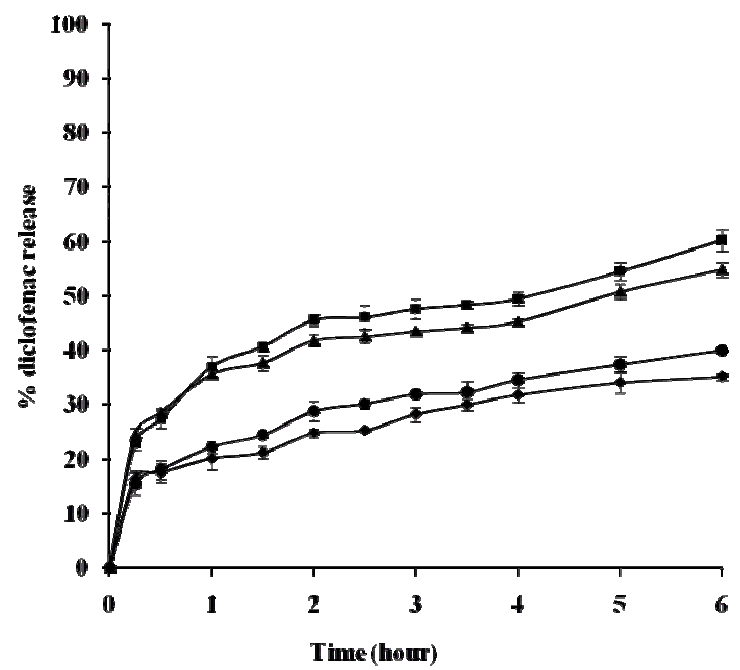

Figure 4. Diclofenac sodium release profile in $0.1 \mathrm{~N} \mathrm{HCl}$ (first 2 hours) and phosphate buffer (last 4 hours) of EC microspheres prepared by emulsion solvent evaporation method. Drug/polymer ratio was 4: $1(\boldsymbol{\bullet}), 1: 1(\boldsymbol{\Delta}), 1: 2.3(\bullet), 1: 4(\bullet)$ (mean $\pm \mathrm{SD}, \mathrm{n}=3$ ).

Release rate of DS from CAP microspheres was slower than that of EC microspheres in $0.1 \mathrm{~N}$ hydrochloric acid solutions ( $\mathrm{pH}$ 1.2) but was faster in case of phosphate buffer solution ( $\mathrm{pH}$ 6.8). First of 
all, microspheres of both EC and CAP were tested for dissolution in $0.1 \mathrm{~N} \mathrm{HCl}$ solutions. Release data were A1-24.78\%, A2-28.84\%, A3-41.87\% and A4-45.60\% from EC microspheres whereas release data were only B1-9.48\%, B2-10.08\%, B3-2.37\% and B4$5.03 \%$ from CAP microspheres. Then the microspheres were tested for dissolution again in phosphate buffer solution ( $\mathrm{pH}$ 6.8) for another 4 hours. In this case, release data were A1-35.16, A2$40.04 \%, \mathrm{~A} 3-54.95 \%$ and $\mathrm{A} 4-60.32 \%$ from $\mathrm{EC}$ microspheres whereas release data were $\mathrm{B} 1-89.80 \%$,

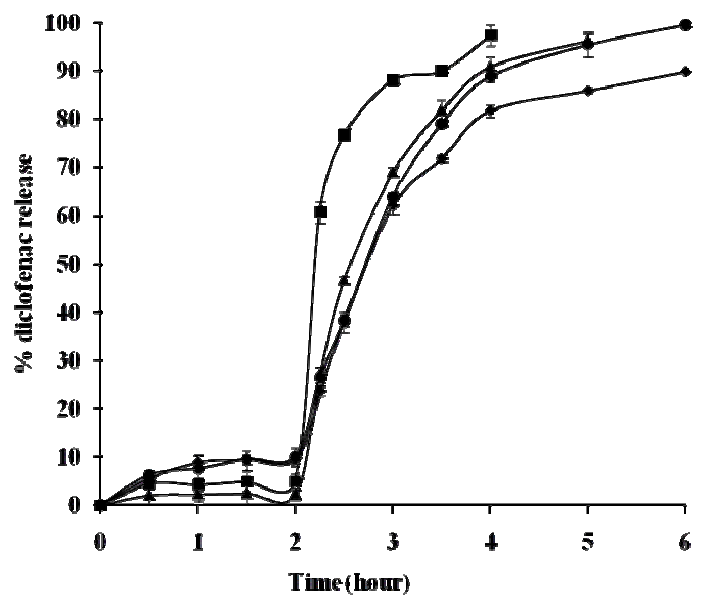

Figure 5. Diclofenac sodium release profile in $0.1 \mathrm{~N} \mathrm{HCl}$ (first 2 hours) and phosphate buffer (last 4 hours) of CAP microspheres prepared by emulsion solvent evaporation method. Drug/polymer ratio was 4: $1(\bullet), 1: 1(\boldsymbol{\Delta}), 1: 2.3(\bullet), 1: 4(\bullet)$ (mean $\pm \mathrm{SD}, \mathrm{n}=3$ ).

B2-99.60\%, B3-99.67\% and B4-99.43\% from CAP microspheres. In fact, formulation B4 released almost all drugs within 2 hours in phosphate buffer solution. This may be due to the enteric coating nature of $\mathrm{CAP}^{18-20}$. Being enteric coating polymer in nature, CAP resists prolonged contact in strongly acidic media but dissolves in mildly acidic or neutral intestinal environment. ${ }^{21}$ On the contrary, EC has a $\mathrm{pH}$ independent solubility profile where it shows a good solubility in polar solvents. ${ }^{21}$ This $\mathrm{pH}$ nondependent solubility of EC caused dissolution of DS in both acidic and neutral media. Due to this reason, no significant variation in release rate of DS was observed between acidic and neutral dissolution media.
Dissolution profile of EC microspheres was different from that of CAP microspheres. The drug release profiles of EC microspheres provided linear relationships for Higuchi plotting (Figure 6). These findings indicated that the internal structure of the EC microspheres was a polymeric matrix containing dispersed drug. On the other hand, the CAP microspheres did not follow Higuchi equation. They followed first order equation.

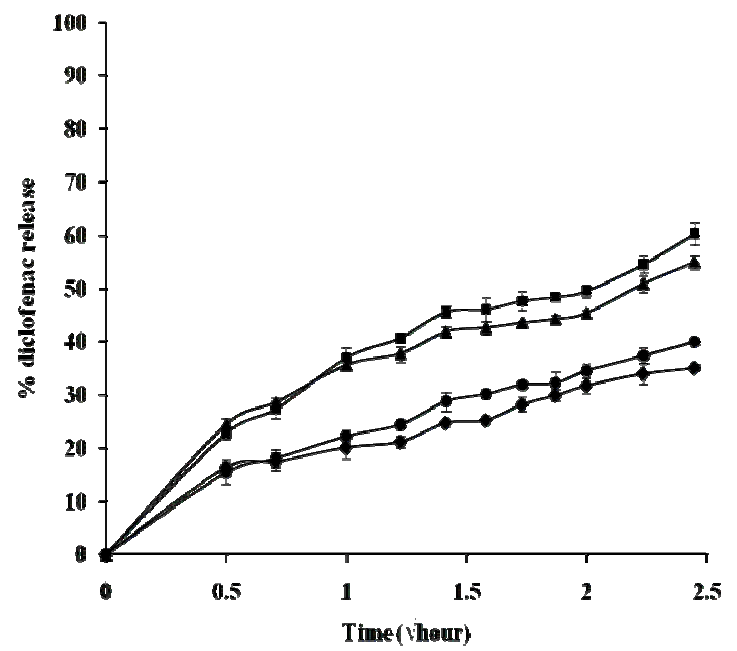

Figure 6. Higuchi release curve of diclofenac sodium in $0.1 \mathrm{~N} \mathrm{HCl}$ (first 2 hours) and phosphate buffer (last 4 hours) from microspheres prepared with different concentration of EC. Drug/polymer ratio was 4: $1(\mathbf{\bullet}), 1: 1(\mathbf{\Delta}), 1: 2.3(\bullet), 1: 4(\bullet)$ (mean $\pm \mathrm{SD}, \mathrm{n}=3$ ).

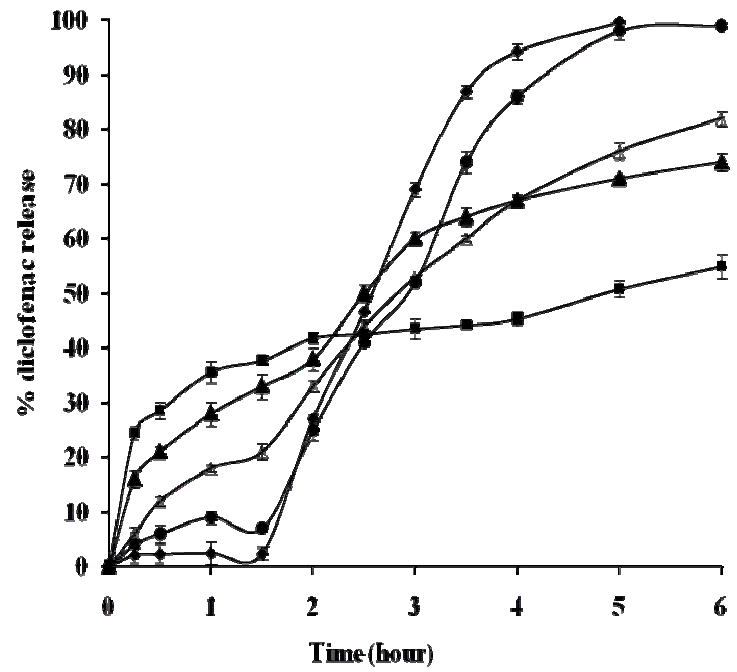

Figure 7. Diclofenac sodium release profile in $0.1 \mathrm{~N} \mathrm{HCl}$ (first 2 hours) and phosphate buffer (last 4 hours) of EC/CAP microspheres prepared by emulsion solvent evaporation method. EC/CAP ratio was 0: $100(\bullet), 25: 75(\bullet), 50: 50(\Delta), 75: 25$ $(\boldsymbol{\Delta}), 100: 0(\mathbf{\square})($ mean $\pm \mathrm{SD}, \mathrm{n}=3)$. 
The difference in drug release behavior suggested structural differences of the wall materials. Ethyl cellulose, an ethyl ether of cellulose, is a long chain polymer of $\beta$-anhydroglucose units joined together by acetal linkages. Drug release from dosage forms, coated with ethyl cellulose, is a function of wall thickness and surface area. That's why DS was found to release slowly from EC microspheres and a diffusion controlled Higuchi release was observed.
On the other hand, cellulose acetate phthalate is a cellulose in which about half the hydroxyl groups are acetylated and about a quarter are esterified with one of the two acid groups of phthalic acid keeping other acid group as free. As CAP dissolves in mildly acidic to intestinal $\mathrm{pH}$, a quicker release of $\mathrm{DS}$ was observed during last 4 hours of dissolution. And the release followed a polymer-concentration dependent first order model.

Table 3. Mean particle size and Drug entrapment efficiency of the microspheres prepared with ethyl cellulose and cellulose acetate phthalate.

\begin{tabular}{|c|c|c|c|c|c|c|}
\hline Batch & $\begin{array}{c}\text { Theoretical load } \\
\text { of DS (\%) }\end{array}$ & $\begin{array}{c}\text { Actual load } \\
\text { of DS (\%) }\end{array}$ & $\begin{array}{c}\text { Loading } \\
\text { efficiency }(\%)\end{array}$ & $\begin{array}{c}\text { Mean population } \\
\text { diameter } \mu \mathrm{m}( \pm \mathrm{SD})^{\mathrm{a}}\end{array}$ & $\begin{array}{l}\text { Mean volume diameter } \\
\qquad \mu \mathrm{m}( \pm \mathrm{SD})^{\mathrm{a}}\end{array}$ & $\begin{array}{c}\text { SSA } \\
\left(\mathrm{m}^{2} / \mathrm{g} X 10^{-2}\right)^{\mathrm{b}}\end{array}$ \\
\hline $\mathrm{A} 1$ & 20 & 18.53 & 92.65 & $545.22 \pm 3.45$ & $885.65 \pm 2.54$ & 0.98 \\
\hline A 2 & 30 & 27.31 & 91.03 & $412.65 \pm 1.87$ & $813.32 \pm 3.11$ & 1.23 \\
\hline A3 & 50 & 42.32 & 84.64 & $398.43 \pm 2.65$ & $725.34 \pm 1.65$ & 1.67 \\
\hline A4 & 80 & 58.12 & 72.65 & $346.76 \pm 2.48$ & $623.91 \pm 4.21$ & 1.76 \\
\hline B1 & 20 & 17.48 & 87.4 & $657.34 \pm 3.01$ & $921.34 \pm 1.34$ & 0.82 \\
\hline B2 & 30 & 26.02 & 86.73 & $541.23 \pm 1.12$ & $843.28 \pm 2.32$ & 1.11 \\
\hline B3 & 50 & 37.32 & 74.64 & $422.61 \pm 1.76$ & $578.54 \pm 2.81$ & 1.84 \\
\hline B4 & 80 & 57.22 & 71.52 & $301.48 \pm 2.13$ & $563.31 \pm 1.65$ & 1.87 \\
\hline $\mathrm{C} 1$ & 50 & 42.67 & 85.34 & $564.75 \pm 3.21$ & $728.22 \pm 2.21$ & 1.61 \\
\hline $\mathrm{C} 2$ & 50 & 39.53 & 79.06 & $501.34 \pm 2.24$ & $629.12 \pm 2.02$ & 1.72 \\
\hline $\mathrm{C} 3$ & 50 & 39.24 & 78.48 & $478.54 \pm 2.34$ & $603.43 \pm 1.34$ & 1.81 \\
\hline
\end{tabular}

All the mean microcapsule sizes are the geometric mean and geometric standard deviation (SD) respectively.

${ }^{a}$ Geometric mean and geometric standard deviation (SD)

${ }^{\mathrm{b}} \mathrm{SSA}=$ Specific surface area of microcapsules

Figure 7 reveals different release profile when the two polymers, EC and CAP, are mixed together to form microspheres and when the same two polymers are used separately. The results confirm that EC could be added in the CAP microspheres to control the release of DS. Especially in the intestinal $\mathrm{pH}, \mathrm{EC}$ showed good release retarding activity of DS from CAP microspheres. This will also reduce the gastrointestinal toxicity of diclofenac sodium associated with excess amount of it in the GI tract.

\section{CONCLUSION}

In this experiment, we have prepared diclofenac sodium microspheres with two different polymers: ethyl cellulose and cellulose acetate phthalate. Microspheres were of spherical in shape and uniform in size distribution. Ethyl cellulose microspheres showed good sustained release behavior both in gastric as well as in intestinal $\mathrm{pH}$. Cellulose acetate phthalate microspheres showed almost no release in gastric $\mathrm{pH}$ but a quick release was observed in case of intestinal $\mathrm{pH}$. Thus both the polymers could be used to prepare sustained release diclofenac sodium microspheres. Especially cellulose acetate phthalate could be an ideal polymer for site specific or enteric coated diclofenac sodium loaded microspheres.

\section{REFERENCE}

1. Todd, P.A. and Sorkin, E.M. 1988. Diclofenac sodium, a reappraisal of its pharmacodynamic and phamacokinetic properties, and therapeutic efficacy. Drugs 35. 244-285.

2. A.G. Gilman, T.W. Ralf, A.S. Nile. The Pharmacological Basis of Therapeutics. Volume I.B. Maxwell Publishing Corporation, 8th edition, 1991, p. 669.

3. Jani G.K, Gohel M.C. 1997. Effects of selected formulation parameters on the entrapment of diclofenac sodium in ethyl cellulose microspheres. J. Control. Release. 43, 245-250.

4. Sheu MT, Chou HL, Kao CC, Liu CH and Sokoloski TD. 1992. Dissolution of diclofenac sodium from matrix tablets. Intl. J. Pharmaceutics. 85, 57-63. 
5. Wang DP, Yang MC, Wong CY. 1997. Formulation development of oral controlled release pellets of diclofenac sodium. Drug Dev. Ind. Pharm. 23, 1013-1017.

6. Bakan, J.A. and Anderson, J.L., 1976. Microencapsulation. The Theory and Practice of Industrial Pharmacy, edited by L. Lachman, H.A. Lieberman and J.L. Kanig (Philadelphia: Lea and Febiger), pp. 420-438.

7. Li, S.P., Kowalski, C.R., Feld, K.M. and Grim, W.M. 1988. Recent advances in Microencapsulation Technology and equipment. Drug Dev. Ind. Pharm. 14, 353-376.

8. Ismail, N., Harris, M.S., and Nixon J.R., 1984. Particle size analysis of gelatin-acacia coacervate and ethylcellulosewalled microcapsules. J. Microcapsul. 1, 9-19

9. Nixon, J.R., and Meleka, M.R. 1984. The preparation and characterization of ethyl cellulose-walled theophylline microcapsules. J. Microcapsul. 1, 53-64.

10. Lu B, Wen R, Yang H, He Y. 2007. Sustained-release tablets of indomethacin-loaded microcapsules: preparation, in vitro and in vivo characterization. Int $J$ Pharm. 21; 333, 87-94. Epub 2006 Oct 6

11. Biju SS, Saisivam S, Rajan NS, Mishra PR. 2004. Dual coated erodible microcapsules for modified release of diclofenac sodium. Eur J Pharm Biopharm. 58, 61-7

12. Islam, M.S., Rahman, A., Islam, M.K., Chowdhury, J.A., Jalil., R. 2009. Preparation and characterization of Polyvinyl Acetate (Kollidon SR) microspheres containing diclofenac sodium II: effect of core loading. Dhaka Univ. J. Pharm. Sci. 8, 117-122.

13. Rodriguez, M., Jose, L., Villa-Jato, J. L. and Torres, D., 1998. Design of a new multiparticulate system for potential site-specific and controlled drug delivery to the colonic region. J. Control. Release. 55, 67-77.
14. Lee, J. H., Park T. G. and Choi, H. K., 2000. Effect of formulation and processing variables on the characteristics of of microspheres for water soluble drugs prepared by w/o/o double emulsion solvent diffusion method. Intl. J. Pharmaceutics. 196, 75-83.

15. Younan, B. B. C., Jacson, T. L., Dickens, L, Hernandez, C. and Ababio, G. O., 2001. Protein release profiles and morphology of biodegradable microcapsules containing an oily core. J. Control. Release. 76, 313-326.

16. Alex, R. and Bodmeier, R., 1990. Encapsulation of watersoluble drugs by a modified solvent evaporation method I. Effect of process and formulation variables on drug entrapment. J. Microencaps. . 7, 347-353.

17. Kristmundsdóttir, T., Gudmundsoon, O. S. and Ingvarsdottir, K., 1996. Release of Diltiazem from Eudragit microparticles prepared by spray-drying. Intl. J. Pharmaceutics. 137, 159165.

18. Takenaka, H. Kawashima, Y. and Lin, S.Y. 1980. Preparation of enteric-coated microcapsules for tableting by spray-drying technique and in vitro simulation of drug release from the tablet in GI tract. J. Pharm. Sci. 69, 13881392.

19. Maharaj, I. Nairn, J.G. and Campbell, J.B. 1984. Simple rapid method for the preparation of enteric-coated microspheres. J. Pharm. Sci. 73, 39-42.

20. Beyger, J.W. and Nairn, J.G. 1986. Some factors affecting the microencapsulation of pharmaceuticals with cellulose acetate phthalate. J. Pharm. Sci. 75, 70-74.

21. Kibbe A. H. 2000. Handbook of Pharmaceutical Excipients. American Pharmaceutical Association, $3^{\text {rd }}$ ed: p. 99. 